\title{
A longitudinal study of pornography use before and during the COVID-19 pandemic in a nationally representative sample of Americans
}

\author{
Joshua B. Grubbs, ${ }^{1}$ Samuel L. Perry, ${ }^{2}$ Shane W. Kraus, ${ }^{3}$ Jennifer T. Weinandy ${ }^{1}$
}

Of the many changes in daily life brought about by the COVID-19 pandemic, social distancing efforts and governmentally mandated lockdowns were among the most drastic. Coinciding with these changes, popular pornography websites made some previously premium content available for free, spurring dramatic increases in traffic to these websites. This increase in time spent at home and reported increases in traffic to specific pornographic websites led to some speculation that pornography use might generally increase over the course of the pandemic and that problematic use might also increase. To test these speculations and quantify the effects of the pandemic and its associated restrictions on social behaviors on pornography use, we analyzed data from a longitudinal sample of American adults. Baseline, nationally representative data were collected in August, 2019 via YouGov (N=2,518). Subsequent data were collected in February, 2020 ( $n=1,677)$, May, 2020 ( $n=1,533)$, August, 2020 ( $n=1,470)$, and October, 2020 (n=1,269). Results indicated that, in May, 2020, immediately following the height of the first wave of pandemic related lockdowns, more people reported past month pornography use than at any other time point. Among those who reported use in May, 2020, only 14\% reported increases in use since the start of the pandemic, and their use returned to levels similar to all other users by August of 2020. In general, pornography use trended downward over the pandemic, for both men and women. Problematic pornography use trended downward for men and remained low and unchanged in women. Collectively, these results suggests that many fears about pornography use during pandemic related lockdowns were largely not supported by available data

In 2020, the spread of the novel SARS-CoV-2 virus and the resulting COVID-19 pandemic disrupted life across the globe. Coinciding with efforts to "flatten the curve" (i.e., a reference to slowing the spread of the novel coronavirus so as to avoid overwhelming limited healthcare resources; Matrajt \& Leung, 2020), one of the world's largest pornographic websites, Pornhub.com, announced plans to make their premium content free to individuals living in parts of the world where lockdowns were in place (Wilson, 2020). As a result of this free access, Pornhub reported increases (38-61\%) in web-traffic to their website from regions affected by severely restrictive stay-at-home orders and lockdowns (Pornhub Insights, 2020). These increases were above and beyond Pornhub's already incredible average in 2019 of over 115,000,000 unique visits per day (Grubbs \& Kraus, 2021; The 2019 Year in Review - Pornhub Insights, 2019). Similarly, internet search data from Google suggested that there was an increased interest in pornography during the most restrictive phases of many countries' lockdowns (Zattoni et al., 2020).

The above described increases in internet pornography use garnered international media attention (Turak, 2020), as well as attention from scholars studying the use and effects of pornography (Grubbs, 2020). Additionally, there were calls from mental health researchers and professionals warning of the potential for the COVID-19 pandemic and associated social-distancing measures to exacerbate problematic pornography use (Király et al., 2020; Mestre-Bach et al., 2020; Sinclair et al., 2020), with similar concerns raised for other behaviors such as problem gambling (Håkansson et al., 2020). Even so, at present, empirical research evaluating the actual progression of pornography use behavior over the initial months of the pandemic has been largely lacking. Accordingly, the present study made use of a longitudinal design in a national sample of American adults to evaluate trends in

\footnotetext{
${ }^{1}$ Department of Psychology, Bowling Green State University

2.Department of Sociology, University of Oklahoma

3.Department of Psychology, University of Nevada, Las Vegas

Correspondence regarding this article can be sent to Joshua B. Grubbs, Department of Psychology, Bowling Green State University, 400 E. Merry Street, Bowling Green, OH, 43403. Email: GrubbsJ@BGSU.edu.

The authors declare no conflict of interest.

Data collection for this work was supported by grants to the first author (JBG) from the Charles Koch Foundation.
} 


\section{Porndemic}

pornography use before and during the COVID-19 pandemic.

\section{Motivations for Pornography Use}

Given the rather unprecedented nature of the COVID-19 pandemic in modern times, there is an absence of research examining how a global pandemic and associated virus containment measures have influenced individual pornography use. However, there is a rather extensive body of research related to motivations for pornography use which may be informative and could provide some insights into why we might expect to see patterns of pornography use change within the context of COVID-19.

The single most common reason for pornography use is pleasure (Grubbs, Wright, et al., 2019). People view pornography out of a desire to obtain sexual pleasure or satisfy sexual desire (Brown et al., 2017). Pornography is often used to enhance pleasure associated with masturbation or to make masturbation easier (Emmers-Sommer, 2018; Perry, 2019a). Therefore, to the extent that social isolation and other factors associated with the pandemic led people to seek alternative forms of pleasure or entertainment, it is plausible that the pandemic may have led some people to use more pornography.

There is also compelling evidence that people use pornography for a range of hedonic reasons extending beyond just pleasure (Grubbs, Wright, et al., 2019). That is, pornography use is also often a result of coping motivations or a desire to reduce negative affect (Bőthe et al., 2020; Grubbs, Wright, et al., 2019). Using pornography in response to stress, depressive symptoms, and anxiety is commonly reported in studies of pornography use motivations (Baltazar et al., 2010; Paul \& Shim, 2008), often being the second most common reason for such use after the pleasure-seeking reasons mentioned above (Grubbs, Wright, et al., 2019). Although not all people have reported increases in distress associated with the pandemic (Zacher \& Rudolph, 2021), there is certainly evidence that many people experienced increases in depression, anxiety, and various other symptoms of distress (Ettman et al., 2020).

There is also evidence that pornography is often used to cope with boredom (Chen et al., 2013; Paul \& Shim, 2008; Rothman et al., 2015; Schenk, 2009). Although there is certainly evidence that some people have had more positive experiences associated with the

\footnotetext{
${ }^{2}$ Throughout, we use the term "self-perceived problematic pornography use" and the acronym PPU to refer to self-reported
}

pandemic (Zacher \& Rudolph, 2021), boredom increased quite substantially in regions facing severe movement restrictions related to COVID-19 (Brodeur et al., 2020). This raises the possibility that pornography use might increase as a result pandemic related social distancing measures. More simply, it is plausible that people affected by social distancing orders may have chosen to use pornography as a means of coping with boredom.

Some evidence also suggests that pornography use can be motivated by loneliness (Butler et al., 2018; Yoder et al., 2005), which may be intuitively relevant to behaviors in the COVID-19 pandemic. However, studies tracking loneliness among Americans during the acute phases of the pandemic have been mixed (Guntuku et al., 2020; Luchetti et al., 2020). Specifically, some studies have reported no substantive changes in loneliness over the pandemic (Luchetti et al., 2020), whereas others have reported evidence of increases in loneliness (Guntuku et al., 2020). If loneliness were to have consistently increased, it is plausible that some individuals might use pornography more to cope with such feelings. This speculation seems to be supported by analyses of Google search data which found that general interest in pornography increased in various places during the same time periods as restrictive lockdowns (Zattoni et al., 2020).

In sum, while there is virtually no prior literature on pornography use in the context of a pandemic, there is ample evidence that pornography use may be motivated by factors, such as pleasure seeking, loneliness, and boredom reduction, that are particularly salient in the wake of the COVID-19 pandemic. Additionally, given the inherent stressors associated with a global pandemic and the disruptiveness of this pandemic (Guntuku et al., 2020), it is also possible that pornography use might increase as a result. Importantly, coping motivations for pornography use are particularly concerning, as pornography use in response to negative affect is linked to more problematic ${ }^{2}$ pornography use (i.e., compulsive, dysregulated, or excessive use) of pornography in general (Bőthe et al., 2020; Reid et al., 2011). Indeed, this specific possibility has been posited by behavioral addiction researchers and mental health professionals (Mestre-Bach et al., 2020) but remains untested with robust empirical data.

feelings of being out-of-control, dysregulated, or compulsive in pornography use 


\section{Porndemic}

If self-reported PPU were to increase over the course of the pandemic, this would be of particular concern given a body of research suggesting that selfreported PPU is associated with a range of mental health issues, such as greater levels of stress, depression, and anxiety (Droubay et al., 2020; Grubbs, Perry, et al., 2019; Guidry et al., 2019). Additionally, self-reported PPU is often associated with greater distress in romantic relationships (Leonhardt et al., 2018; Leonhardt \& Willoughby, 2019), and greater distress in one's religious life (Burke \& Haltom, 2020; Grubbs et al., 2017; Perry, 2019b). In short, self-reported PPU is associated with a range of indicators of poor well-being, and, given these associations, further work is needed to understand whether or not self-reported PPU may have changed over the course of the COVID-19 pandemic as previous works have speculated (Mestre-Bach et al., 2020).

\section{The Present Study}

Given the unprecedented nature of the COVID19 pandemic, the primary purpose of the present work was to describe longitudinal changes in pornography use habits in the American public over the early course of the pandemic, with a particular focus on such use during the earliest and most-restrictive lockdowns in the U.S.. That is, rather than taking a confirmatory or hypothesis driven approach, we sought to take an exploratory, descriptive, and longitudinal one for the current study. Even so, given that pornography is sometimes used to ameliorate boredom and cope with anxiety and or stress, there was some reason to expect that pornography use would likely increase during the COVID-19 pandemic, particularly earlier in the pandemic when social distancing and mandated lockdowns were at their first peak and both anxiety and loneliness related to COVID-19 began to spike (Guntuku et al., 2020).

Additionally, given concerns about the potential for the pandemic and associated restrictions on social behavior to result in increased PPU (Király et al., 2020; Mestre-Bach et al., 2020), we also sought to examine how self-reported PPU progressed during the pandemic. Finally, given the known links between general psychological distress and self-reported PPU, we also sought to examine how psychological distress progressed over the course of the pandemic and how it related to pornography use in general and self-reported PPU. Given that a number of studies have already examined how various mental health concerns have progressed over the pandemic, our primary aim in exploring psychological distress was to account for how it related to pornography use patterns.

\section{METHOD}

The present work represents analyses of data collected as a part of a larger, longitudinal project assessing personality, mental health, social relatedness, and public discourse over time (Grubbs, Tosi, et al., 2019). Below, we describe the methodology of this project salient to the current work. More details regarding this project and the measures included in the total project are available via the Open Science Framework at https://osf.io/zbg3d/. Data for this project and associated code can be found on the OSF as well: https://osf.io/8ke7x/?view only=6950b829653b4a6e908d $\underline{82 \mathrm{df3} 367675 \mathrm{f}}$.

\section{Participants and Procedure}

Participants were recruited via YouGov opinion polling and matched to U.S. nationally representative norms for age, gender, race, education, and census region as of the 2016 American Community Survey $(N=$ 2,518). Participants were predominantly (64.1\%) White/Caucasian, followed by African American/Black (12.0\%); Latinx/Hispanic (15.7\%); Asian/Pacific-Islander (3.3\%); American Indian (0.9\%); Other (2.5\%); and Mixed (1.5\%). Participants completed baseline measures in the first week of August, 2019. Subsequent to this initial survey, participants who completed baseline measures were invited to complete follow-up measures in the first week of February, $2020(n=1,677)$, the first week of May, $2020(n=1,533)$, the first week of August, $2020(n=1,470)$, and the second week of October, 2020 $(n=1,269)$. At each follow-up, all participants from baseline were invited to complete subsequent waves. This resulted in a total of 868 participants that completed all 5 waves.

\section{Measures}

\section{Psychological Distress}

Consistent with recent research on psychological distress in the context of the COVID-19 pandemic (Daly \& Robinson, 2020), at all five time points, we used the Patient Health Questionnaire - 4 (Kroenke et al., 2009). Derived from the longer Patient Health Questionnaire - 9 (Kroenke et al., 2001) and the Generalized Anxiety Disorder -7 (Spitzer et al., 2006), the PHQ-4 assesses frequency of four distress symptoms in response to the prompt, "Over the last two weeks how often have you been bothered by..." Participants respond to this prompt by rating the frequency with which they have experienced two symptoms of anxiety 


\section{Porndemic}

("feeling nervous, anxious, or on edge" and "not being able to stop or control worrying") and two symptoms of depression ("little interest or pleasure in doing things" and "feeling down, depressed, or hopeless") on a scale of 1 (not at all) to 4 (nearly every day). Generally considered to be a rough screening measure for both depression and anxiety, the PHQ-4 is a useful index of general psychological distress (Kroenke et al., 2009).

\section{Pornography Use Frequency}

To assess trends in pornography use frequency, we asked participants to respond to how frequently they had viewed pornography since the previous survey. At each time point, participants reported how often they had "viewed pornography alone (without a partner)." For the present work, we defined pornography for the participants as: "Pornography refers to any sexually explicit films, video clips or pictures displaying the genital area, which intends to sexually arouse the viewer; this may be seen on the internet, in a magazine, in a book, or on television."

At Wave 1, participants responded to the prompt "In the past 12 months, how often have you viewed pornography alone (without a partner)..." on a scale of 1 (never) to 8 (once a day or more).

At our second wave, six months after the initial survey, participants responded to the same prompt, but only referring to the past 6 months. Responses were coded on the same scale as at baseline on a scale of 1 (never) to 8 (once a day or more).

At our third wave, taken the first week of May 2020, participants reported to the same prompt as above, but only referring to the past month. Given the change in time period referred to (i.e., 1 month vs. 6 or 12 months), participants responded on a scale of 1 (never) to 7 (once a day or more).

At our fourth and fifth waves, collected 12 and 15 months after baseline respectively, participants reported the frequency of the pornography use over the past 3 months on a scale of 1 (never) to 8 (once a day or more).

Given that the above frequency measures were collected with slightly different scale ranges (i.e., Waves $1,2,4$, and 5 ranged from 1-8 and referred to periods of 12 months, 6 months, and 3 months, while Wave 3, which referred to only one month, ranged from 1-7), we transformed these responses to a $0-5$ scale where $0=$ not within the past month, $1=$ within the past month, $2=$ two or three times a month, $3=$ once a week, $4=$ a few times a week, and $5=$ once a day or more. For our average frequency measures at August 2019, February 2020, August of 2020, and October of 2020, we converted scores so that answers of "Never," "Once or Twice," and "A Few Times" were equal to 0, answers of "Once a Month" were equal to 1, answers of "two or three times a month" were equal to 2, answers of "Once a week" were equal to 3, answers of "a few times a week" were equal to 4, and answers of "Once a day or more" were equal to 5. For our frequency measure in May of 2020, which only referred to the past month, we converted scores so that answers of "never" were equal to 0 , answers of "once or twice" were equal to 1, answers of "a few times" and "two or three times" were equal to 2, answers of "once a week" were equal to 3 , answers of "a few times a week" were equal to 4 , and answers of "once a day or more" were equal to 5 . This adjusted frequency variable, based on past month use only, was used in all analyses.

\section{COVID-19 Related Changes in Pornography Use}

At our third wave (May of 2020), among those that endorsed at least some use over the past month, we asked if there were changes in their pornography use since the beginning of the pandemic. Specifically, participants responded to the prompt: "Since the beginning of the COVID-19 pandemic, has your pornography use increased, decreased or stayed the same?" by selecting one of these responses.

\section{Self-Perceived Problematic Pornography Use.}

Throughout, we conceptualized problematic pornography use (PPU) as self-reported problems in regulating, reducing, or controlling the amount of pornography consumed. Individuals that endorsed pornography use within the time periods referenced by the above frequency measures (i.e., within 12 months of baseline, within 6 months of Time 2, within 1 month of Time 3, and within 3 months of Times 4 and 5) also completed the Cyber Pornography Use Inventory-4 (CPUI-4; Grubbs \& Gola, 2019). Based on the earlier Cyber Pornography Use Inventory-9 (Grubbs et al., 2015) and Cyber Pornography Use Inventory (Grubbs et al., 2010), the CPUI-4 measures problematic pornography use on a four-item scale. Participants responded on a scale of 1 (strongly disagree) to 7 (strongly agree) to four statements ("I believe I am addicted to Internet pornography," "I feel unable to stop my use of online pornography," "Even when I do not want to view pornography online, I feel drawn to it," and "I have put off things I needed to do in order to view pornography"). 


\section{Porndemic}

\section{Plan for Analyses}

Given that the primary aims of the present work were descriptive and exploratory, the majority of our analyses did not take a hypothesis-testing approach. That is, most of our analyses were conducted from an exploratory standpoint, with a goal of maximizing fit while maintaining parsimony.

For all included variables, descriptive statistics and Pearson correlations were conducted using the psych package (Revelle, 2014) for R statistical software (R Core Team, 2018). All test-statistics were adjusted using the Holm-correction (Revelle, 2014)

Analyses of Variance were conducted to determine if those who reported an increase in pornography use during the restrictive portion of COVID-19 lockdowns actually differed with regards to the frequency of pornography viewing they reported. Any post-hoc comparisons conducted were conducted using a Holm correction.

We also conducted a series of latent growth curve (LGC) analyses using the lavaan package (Rosseel, 2012) for R statistical software (R Core Team, 2018). For these analyses, we assumed a linear growth trajectory for all key variables, as past work has demonstrated that linear paths better fit the trajectory of pornography use and self-reported PPU over time (Grubbs et al., 2020). For each LGC, we used diagonally weighted least squares estimation (DWLS), as such estimation is preferable for non-normal and ordinal data and is robust against possible violations of general regression assumptions such as homoscedasticity and normality of residuals (Flora \& Curran, 2004; Li, 2016; Mîndrilă, 2010; Wang \& Cunningham, 2005). Missing data were handled with Multiple Imputation using the Amelia (Honaker et al., 2011), miTools (Lumley, 2019), and semTools (Jorgensen et al., 2020) packages for R statistical software. Results for all LGC's represent pooled results across 24 imputed datasets using Rubin's (1987) rules for pooling point and SE estimates. For all LGC's, we report multiple fit indices, including the $\chi^{2}$ values, Comparative Fit Indices (CFI), Tucker-Lewis Indices (TLI), Root Mean Square Error of Approximation (RMSEA), and Standardized Root Means Square Residual (SRMR).

All analyses were conducted using a multigroup approach, with two groups specified by gender. For each key variable of interest, we first specified linear univariate LGCs (i.e., one LGC for each variable), with our defined unit of time being three months. This resulted in a series of LGCs for which linear slopes were defined by baseline measurements (August of 2019) fixed to zero, Time 2 measurements (February of 2020) fixed to two (i.e., two units of three months each), Time 3 measurements (May of 2020) fixed to three, Time 4 measurements (August of 2020) fixed to four, and Time 5 measurements (October of 2020) fixed to five. Additionally, for each key variable, we specified an alternate LGC with the same specifications as above, but with Time 3 measurements - those taken at the height of the first COVID-19 related lockdowns-left unfixed and allowed to vary freely. This alternate specification (allowing Time 3 values to be unfixed and vary freely) allowed for the possibility that changes in May of 2020 might deviate substantially from the overall linear trend we expected to find in the data.

\section{Results}

\section{Correlations}

Pearson correlations demonstrated that almost all associations between variables were significant, though the magnitude of such associations varied substantially. These results are available in Table 1. Within and across time points, psychological distress correlated with pornography use frequency from $r=.06$, $p=.080$ to $r=.16, p<.001$. Similarly, correlations within and across time points between psychological distress and self-reported PPU ranged from $r=.08, p=.030$ to $r=.27$, $p<.001$. Finally, all correlations between frequency of pornography use and self-reported PPU were much more substantial, ranging from $r=.25, p<.001$ to $r=.40$, $r<.001$.

\section{Frequency}

With regards to pornography use frequency at the various time points, there were notable fluctuations. These results are available in Table 2 . At baseline, $43.4 \%$ of participants reported not having viewed pornography in the past year and $35.2 \%$ of participants reported using pornography, on average, at least once per month (59\% of men and $21 \%$ of women). By February of 2020 , only $28.1 \%$ of participants reported pornography, on average, at least once per month since baseline ( $45 \%$ of men and $12 \%$ of women). In May of 2020, which was our first pandemic measurement point, coinciding with the most restrictive first wave of lockdowns in most regions of the U.S., $62.1 \%$ of participants reported not having viewed pornography at all within the past month, and $37.9 \%$ of participants reported using pornography at least once in the past month (58\% of men and 19\% of women). In August of 


\section{Porndemic}

2020 , only $23 \%$ reported using pornography at least once in the past month (38\% of men and $8 \%$ of women). Finally, by October of 2020, only 21\% reported any pornography use in the month prior to the survey $(37 \%$ of men and $7 \%$ of women).

When we examined those who reported at least some pornography use within one month of Time 3 $(n=578)$, we found that the majority reported that their pornography use had not changed since the start of the pandemic $(66 \% ; n=379)$, whereas a smaller number reported their use had decreased $(20 \%, n=116)$, and an even smaller number reported their use had increased ( $14 \%$ of those that reported use, $n=83,5 \%$ of all respondents). In short, $86 \%$ of those who reported any pornography use in the past month prior to our survey in May of 2020 reported either consistency or reduction in their pornography use since the outset of the pandemic. Analyses of Variance of pornography use frequency at each time point, based on reported increases, decreases, or stability of pornography use at time 3, revealed that there were no differences in pornography use frequency at Time $1(F[1,576]=0.01$, $p=.929)$, Time $2 \quad(F[1,503]=0.52, \quad p=.472)$, Time 4 $(F[1,481]=1.03, p=.310)$, or Time $5(F(1,392)=0.273, p=.602)$. However, there were significant differences in pornography use frequency reported at Time 3 $(F[1,576]=16.03, p<.001)$. Post-hoc pairwise comparisons with Holm-adjusted test statistics demonstrated that those who said their pornography use had increased since the start of COVID-19 also reported higher levels of pornography use (slightly higher than once per week; $M=3.30, S D=1.33$ ) than those who reported their pornography use had decreased since the start of COVID-19 (about 2-3 times a month; $M=2.03, S D=1.18$ ) and those who stated that their use had stayed the same since the start of the pandemic (slightly higher than 2-3 times per month; $M=2.37, S D=1.39$ ). Additionally, post hoc pairwise comparisons revealed significant differences between those who reported decreases and those who reported that their use had stayed the same. These findings are summarized in Figure 1. 


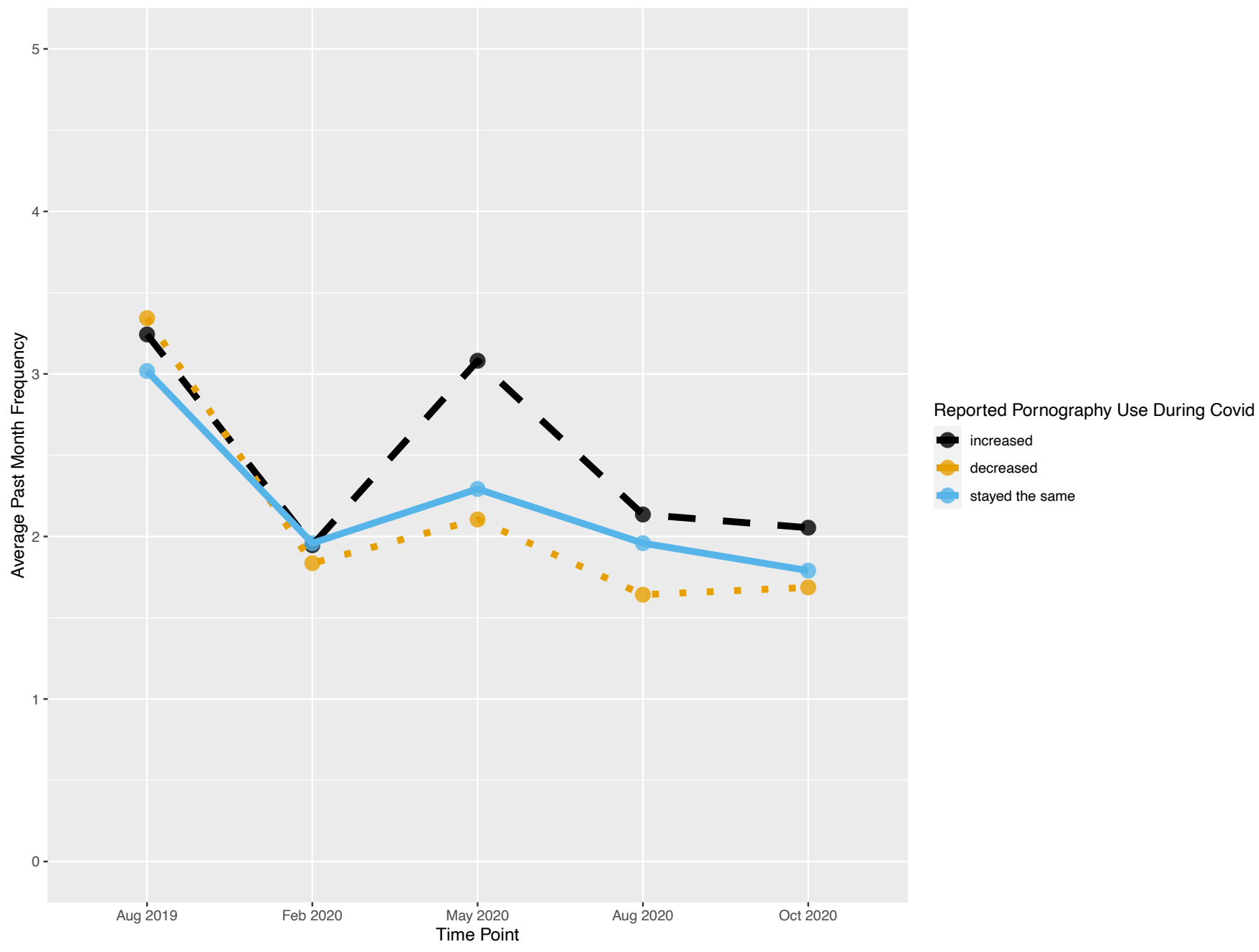

Figure 1. Analysis of frequency of pornography use over time among those who reported increased, decreased, or consistent use during COVID-19. Y-axis values should be interpreted as follows: $0=$ not within the past month, $1=$ within the past month, $2=$ two or three times a month, $3=$ once a week, $4=$ a few times a week, and $5=$ once a day or more,

In short, at the beginning of May 2020, a minority of individuals reported their pornography use had increased since the beginning of the COVID-19 pandemic, which corresponded to higher levels of reported pornography use at this time point. However, by August of 2020, their use had returned to levels indistinguishable from those who denied increases in use during the early part of the pandemic, and this continued through October of 2020. ${ }^{3}$

\footnotetext{
${ }^{3} \mathrm{We}$ also considered that living situation may influence these trends. The data for the present study did include information about baseline (August, 2019) marital status and parenthood status. However, this data was not re-collected at later time points, and we did not assess whether or not individuals were spending more time at home with other people (i.e., locked down at home with others). Chi-square analyses of Time 3
}

\section{Latent Growth Curves}

As discussed earlier, our growth curve analyses took an iterative approach by first conducting singleprocess LGCs for each key variable, then examining parallel process growth curves. Results for single process growth curves are available in Table 3. Results for our dual-process growth curve are available in Tables 4 and 5.

\section{Psychological Distress}

(May, 2020) self-reports of pornography use increasing, decreasing, or staying the same since the start of the pandemic found no differences in distributions of responses based on marital/cohabitation status at baseline $\left(\chi^{2}[2]=3.93, p=.140\right)$ or having children under the age of $18\left(\chi^{2}[2]=.001, p=1.00\right)$. 
For psychological distress, we specified two LGC models. In our first model, we specified a linear growth trajectory with all timepoints fixed to such a trajectory, which demonstrated excellent fit $(\chi 2(20)=46.36, p=.001, \mathrm{CFI}=.991$, TLI=.991, RMSEA=.016, $\mathrm{SRMR}=.022)$.

For our second LGC for psychological distress, we again specified a linear growth trajectory, but left our third timepoint (May of 2020) unfixed and allowed it to load freely. However, the fit of this model was not better than the previous linear model with each time point fixed $\left(\Delta \chi^{2}[2]=0.844, p=.656\right)$. Accordingly, we retained our original model with each time point fixed.

In our retained model, with all time-points fixed to a linear growth trend, our results revealed that psychological distress did not demonstrate any meaningful change over time. Specifically, neither the mean nor the variance of the slope of psychological distress were statistically significant (See Table 3) for men or women, indicating no general trend in distress over time and no specific variability across participants. Put simply, psychological distress, as measured by the PHQ-4, did not change over time in our sample.

\section{Past Month Pornography Use}

For pornography use frequency within the past month, we specified two LGC models. In the first LGC, we specified a linear growth trajectory with each timepoint fixed to a linear trend. This model demonstrated excellent fit $(\chi 2(20)=194.36, \quad p<.001$, $\mathrm{CFI}=.988, \mathrm{TLI}=1.00, \mathrm{RMSEA}=.043, \mathrm{SRMR}=.038)$.

In our second LGC for past-month pornography use we constrained timepoints 1 (August of 2019), 2 (February of 2020), and 4 (August of 2020) to a linear trend, but did not constrain or specify a loading for our third time point (i.e., May of 2020). We specified this alternate model in order to allow the model to rescale time to determine if a non-linear trend better fit our data or if there was substantial divergence to the linear trajectory during the time point most affected by COVID-19 related lockdowns. However, this model's fit was not significantly better or worse than our linear model $\left(\Delta \chi^{2}[2]=2.83, p=.243\right)$. Accordingly, we retained our linear model with each time point constrained to a linear trend.

Our retained LGC for pornography use frequency revealed a clear, linear negative trend (See Table 3) for both men and women. That is, over time, pornography use frequency trended down. Moreover, the standardized covariance (i.e., the correlation) between the latent intercept and the latent slope of pornography use frequency was also negative for both men and women (See Table 3), indicating that individuals who reported greater use at the baseline decreased their pornography use at a faster rate than those who reported less pornography use at the baseline.

\section{Self-Reported Problematic Pornography Use}

For self-reported PPU, we specified two LGC models. In our first LGC model, we specified a linear LGC with each timepoint fixed to a linear trend. This model demonstrated excellent fit $(\chi 2(20)=4.54, p=1.00$, $\mathrm{CFI}=1.00, \mathrm{TLI}=1.00, \mathrm{RMSEA}=.000 \mathrm{SRMR}=.022$ ).

In our second LGC, we specified a LGC that did not constrain time-point 3 (i.e., the wave most affected by COVID related lockdowns). Yet, this model again did not demonstrate significantly better fit than our model with all timepoints fixed to a linear trend $\left(\Delta \chi^{2}[2]=3.91\right.$, $p=.142)$. Therefore, we retained our original model. Our retained model showed a clear negative slope for men, and stability for women (i.e., the slope was not significant). Collectively, this suggests that men's PPU generally decreased over time, and women started at low levels of PPU and generally maintained those levels over time.

\section{Dual-Process Latent Growth Curve}

Given that there was no growth or change in psychological distress over time, we did not conduct a dual process LGC involving psychological distress, instead retaining only the intercept for distress in our final analyses. This left us with one dual process LGC to conduct, for self-reported PPU and self-reported pornography use frequency. For this model, we specified a parallel process growth curve for frequency of pornography use and PPU, with an intercept only specified for psychological distress. The fit for this dual process LGC was good $(\chi 2 \quad(216)=213.10, p=.543$, $\mathrm{CFI}=1.00, \mathrm{TLI}=1.00, \mathrm{RMSEA}=.000, \mathrm{SRMR}=.038)$.

In our final dual-process model, both pornography use frequency and self-reported PPU demonstrated clear negative slopes (See Table 4) for men, while only pornography use itself demonstrated a negative slope for women. The intercept of psychological distress was positively related to the intercepts of pornography use in women, but not in men (See Table 5). The intercept of psychological distress was positively related to the intercept of PPU in both men and women. Additionally, the standardized covariance between the intercept for pornography use and slope of 


\section{Porndemic}

pornography use was positive for both men and women (See Table 5), suggesting that both pornography use frequency and self-reports of PPU corresponded to each other over time, with changes in one corresponding to changes in the other. In contrast, the standardized covariance between the intercept for pornography use frequency and the slope of both use frequency and PPU use was negative for both men and women, suggesting that those with higher levels of baseline pornography use showed more rapid decreases in both use and PPU over time. Finally, the standardized covariance between the intercept of PPU and the slope of PPU was also negative for both men and women, suggesting that those with higher levels of PPU at the baseline demonstrated more accelerated decreases in PPU over time.

\section{Discussion}

At the outset of this work, we sought to examine whether or not there was evidence that pornography use had increased in response to the COVID-19 pandemic and associated restrictions on social behavior. Using a longitudinal study that started with a nationally representative sample of adults in the U.S., we examined the extent to which pornography viewing frequency and PPU changed from August of 2019 to October of 2020. Below, we summarize our findings and discuss the implications of the present work in the context of the ongoing COVID-19 pandemic and associated lockdowns.

\section{Pornography in the Pandemic: The Rise and Fall of Pornography Use}

As we noted earlier in this work, the world's largest pornographic website made claims of increased pornography use at the outset of the COVID-19 pandemic during the height of the first wave of lockdowns and stay-at-home orders (Pornhub Insights, 2020). These increases in pornography use occurred in tandem with this same website offering a range of incentives for increased use. Similarly, analyses of internet search data suggested that interest in pornography peaked during the early stages of the pandemic (Zattoni et al., 2020). Collectively, this led to speculation in popular media (Grubbs, 2020) and peerreviewed journals (Király et al., 2020; Mestre-Bach et al., 2020; Sinclair et al., 2020) about the possibility for pornography use to increase over the course of the pandemic. However, the present results indicate that, overall, changes seen in pornography viewing during the first several months of the pandemic were generally minimal and impermanent for both men and women.
Over the course of data collection, we found that the majority $(86 \%)$ of our sample reported either decreases or consistency in their pornography use during the height of pandemic-related lockdowns (i.e., May of 2020). It is important to note that a minority of our sample (5\% of our May, 2020, follow-up sample; corresponding to $14 \%$ of those who viewed pornography within one month of our May, 2020, wave; $14.6 \%$ of men, $13.7 \%$ of women) did report increases in pornography use during the first COVID-19 related lockdowns. However, even for this group, by August of 2020 and continuing into October of 2020, their use had returned to levels indistinguishable from levels of those who reported decreases or that their use had stayed the same. Although a greater percentage of participants reported viewing pornography within the past month in May 2020 than did so at any other follow-up (38\%), the percentages of people reporting past month use in August of 2020 (23\%) and October of 2020 (20.6\%) were substantially lower than prior waves. In short, although it seems that, in May of 2020, more people did indeed view pornography within the past month than at other follow-up points, any increases in use noted early on during the pandemic for both men and women were short lived.

Results from our LGC analyses generally support the above findings. Across five time points, we found no evidence that general psychological distress trended either downward or upward, but rather remained stable over the course of our study. We found clear evidence that pornography use frequency trended toward less use over the course of the pandemic for both men and women. With regards to self-reported PPU, we found that it trended downward for men. For women, PPU neither increased nor decreased, on average. That is, PPU among women remained low and consistently flat without any fluctuations over the five time points.

In sum, although concerns were raised that pornography viewing (and possibly PPU) could increase during the early part of the pandemic (Grubbs, 2020; Turak, 2020), our results do not fully support this conclusion. That is, the above findings suggest that pornography use generally decreased for both men and women over the 15 months of data collection, and, even among those who experienced initial increases in pornography use, such increases were temporary. The general trends for both pornography use and PPU were downward, particularly for men, with little change in 


\section{Porndemic}

PPU for women who started with already low levels of PPU.

\section{Implications}

Despite the public-facing concerns that many public outlets, activists, and even some academic researchers shared, there is little evidence to support the notion that widespread increases in pornography use were a problem among U.S. adults during the early stages of the COVID-19 pandemic and its associated lockdowns. Although it is certainly possible that individual experiences may vary (i.e., some people may have experienced increased PPU), the general trend was for both pornography use and self-reported PPU to decrease over the course of this study. We suspect that the novelty effects of viewing pornography, even with a premium subscription offered to entice new viewers by Pornhub, likely wore off as people adjusted to new routines and allocated their time to working from home or taking on new demands caused by the pandemic (e.g., online schooling for children, caring for family members). Perhaps more simply, as promotional offers of free premium content expired, people may have simply stopped consuming as much pornography. Additionally, as the initial lockdown periods expired and the weather became more amenable to outdoor activities across the U.S., it is also possible that people were spending less time alone at home. Such conjecture is consistent with the previously discussed literature noting that boredom often motivates pornography use and suggests that, as people found alternate ways to spend their time, boredom motivated pornography use likely decreased.

We have largely framed the results of the present work in the context of mandatory lockdowns, rather than in the context of the pandemic itself. Specifically, though lockdowns and restrictions have largely eased in the U.S. since their initial peak in April and May of 2020, the SARS-CoV-2 virus has spread at a much greater rate in the times since those lockdowns expired. Accordingly, it is important to note that the trend of pornography use decreasing over the course of this work has occurred as the objective markers of the pandemic itself have increased. This suggests that, whereas lockdowns, restrictions, and stay-at-home orders in Spring of 2020 did coincide to more people reporting pornography use in May of 2020 than at any other follow-up, pornography use has trended downward even as the spread of the SARS-CoV-2 has trended upward. In short, although speculative, the effects of the pandemic and associated social distancing measures on pornography use seem to have occurred as a result of lockdown efforts (i.e., more boredom, increased free time), rather than responses to the virus itself (i.e., increased use of pornography to cope with fears about the virus).

Of the many explanations for the trends described above, a particularly obvious explanation is that use of pornography trended downward because people were, in general, less likely to have time alone to view pornography. Although some people do report using pornography with their partners, pornography use is most often a solitary activity (Kraus \& Rosenberg, 2014) and quite often hidden from partners (Willoughby \& Leonhardt, 2020). Additionally, among individuals who live with others (e.g., family, roommates), some level of privacy is typically required for one to use pornography. That is, the majority of people are unlikely to regularly view pornography in the company of others, particularly when those others are not prospective sexual partners. Given that social distancing measures and travel restrictions led to people spending more time at home with others, it is quite possible that such measures also led to general downward trends in pornography use, though our data do not allow us to directly test this hypothesis.

Finally, we note that pornography use decreased from baseline measures in August of 2019 to February of 2020 (before the spread of COVID-19 in the U.S.), suggesting that downward trends in use may have happened without the pandemic. In general, it may be that people use less pornography over time. Although we examined pornography viewing over five time points, we did not measure individuals' motives for viewing pornography (e.g., enhancement of dyadic sexual activity, assistance in solitary masturbation, alleviation of boredom or stress); it is possible that individuals' motives for viewing pornography may have changed or shifted throughout the pandemic, particularly as people have found themselves under growing stressors due to recent economic, employment, health, and caregiving challenges attributed to the ongoing COVID-19 pandemic and associated restrictions on activity.

\section{Limitations}

Although results in the current study are novel and shed light on unanswered questions around the possible effects of COVID-19 on pornography viewing behaviors among U.S. adults, they are not without 


\section{Porndemic}

limitations. First, we used a short measure, the Cyber Pornography Use Inventory-4 (CPUI-4; Grubbs \& Gola, 2019), to assess for PPU in the current study. The use of a brief PPU measure for a longitudinal study is advantageous (i.e., reduces burden and time for participants), but it also lacks the diagnostic accuracy of a clinical interview or clinically validated measure. Further work using a validated clinical measure of PPU, such as the Problematic Pornography Consumption Scale (Bőthe et al., 2018), would likely provide a better diagnostic picture of PPU. Second, although it is beyond the scope of this paper, further work is also needed to identify factors (e.g., demographic, clinical, personality) that can predict the development of PPU or changes in PPU status over time, particularly during periods of significant stress or unrest due to the COVID-19 pandemic. Third, we did not examine the possible effects of moral incongruence on self-reported PPU as noted in prior works (e.g., Grubbs, Lee, Hoagland, Kraus, \& Perry, 2020), which suggests that religiousness can moderate the relationships between pornography and self-reported PPU. Fourth, we did not examine the potential effects of pornographic content consumed or whether or not individuals felt as if their preferences in pornographic content shifted or became problematic over the course of the pandemic. We also note that our measure of psychological distress, the PHQ-4, although widely used as a general screening measure of such distress, is not a diagnostically precise instrument and only briefly captures symptoms of internalizing distress. Symptoms of loneliness, feelings of boredom, COVID-19 specific anxiety, and general stress levels associated with pandemic-related lifestyle changes were not assessed and may have demonstrated different trends than what we observed in PHQ-4 scores.

\section{Conclusions}

The present work joins a growing body of research suggesting that the mental health effects of COVID-19 mitigation and containment efforts (i.e., social distancing, regional and national lockdowns, isolation) are complex. Some studies have found general increases in psychological distress during the early days of the pandemic (Guntuku et al., 2020; Pierce et al., 2020), whereas others showed that distress indicators and risk factors, such as loneliness, did not necessarily increase over the pandemic (Luchetti et al., 2020). Still, others showed slight increases in depression and anxiety during the earlier parts of the COVID-19 pandemic (i.e., March- May) that quickly returned to more normal levels as the pandemic wore on (Fancourt et al., 2020). Our work did not find any changes in psychological distress over time, nor did we find any evidence that pornography use frequency, or importantly, PPU increased during the pandemic. Overall, rates of psychological distress remained relatively unchanged (mean score below two out of five), reflecting attenuated ranges for depression and anxiety in the sample over all five waves. Collectively, this suggests that the pandemic has not universally led to increases in psychological distress and potentially concerning behaviors, as some prior works have suggested. Further work is needed to elucidate the short-term and long-term effects of COVID-19 pandemic on psychological distress, addictions, and sexual behaviors among affected individuals

\section{References}

Baltazar, A., Helm, H. W. Jr., McBride, D., Hopkins, G., \& Stevens, J. V. Jr. (2010). Internet pornography use in the context of external and internal religiosity. Journal of Psychology and Theology, 38(1), 32-40. psyh.

Bőthe, B., Tóth-Király, I., Bella, N., Potenza, M. N., Demetrovics, Z., \& Orosz, G. (2020). Why do people watch pornography? The motivational basis of pornography use. Psychology of Addictive Behaviors. https://doi.org/10.1037/adb0000603

Bőthe, B., Tóth-Király, I., Zsila, Á., Griffiths, M. D., Demetrovics, Z., \& Orosz, G. (2018). The Development of the Problematic Pornography Consumption Scale (PPCS). The Journal of Sex Research, 55(3), 395-406. https://doi.org/10.1080/00224499.2017.1291798

Brodeur, A., Clark, A. E., Fleche, S., \& Powdthavee, N. (2020). Assessing the impact of the coronavirus lockdown on unhappiness, loneliness, and boredom using Google Trends.

ArXiv:2004.12129 [Physics]. http://arxiv.org/abs/2004.12129

Brown, C. C., Durtschi, J. A., Carroll, J. S., \& Willoughby, B. J. (2017). Understanding and predicting classes of college students who use pornography. Computers in Human Behavior, 66, 114-121.

https://doi.org/10.1016/j.chb.2016.09.008 


\section{Porndemic}

Burke, K., \& Haltom, T. M. (2020). Created by god and wired to porn: Redemptive Masculinity and Gender Beliefs in Narratives of Religious Men's Pornography Addiction Recovery. Gender $\mathcal{E}$ Society, 34(2), 233-258. https://doi.org/10.1177/0891243220905815

Butler, M. H., Pereyra, S. A., Draper, T. W., Leonhardt, N. D., \& Skinner, K. B. (2018). Pornography Use and Loneliness: A Bidirectional Recursive Model and Pilot Investigation. Journal of Sex $\mathcal{E}$ Marital Therapy, 44(2), 127-137. https://doi.org/10.1080/0092623X.2017.1321601

Chen, A.-S., Leung, M., Chen, C.-H., \& Yang, S. C. (2013). Exposure to Internet Pornography Among Taiwanese Adolescents. Social Behavior and Personality: An International Journal, 41(1), 157-164.

https://doi.org/10.2224/sbp.2013.41.1.157

Daly, M., \& Robinson, E. (2020). Psychological distress and adaptation to the COVID-19 crisis in the United States. Journal of Psychiatric Research, S0022395620310384. https://doi.org/10.1016/j.jpsychires.2020.10.035

Droubay, B. A., Shafer, K., \& Butters, R. P. (2020). Sexual Desire and Subjective Distress among Pornography Consumers. Journal Of Sex $\mathcal{E}$ Marital Therapy, 21. https://doi.org/10.1080/0092623X.2020.1822483

Emmers-Sommer, T. M. (2018). Reasons for Pornography Consumption: Associations with Gender, Psychological and Physical Sexual Satisfaction, and Attitudinal Impacts. Sexuality $\mathcal{E}$ Culture, 22(1), 48-62. https://doi.org/10.1007/s12119-017-9452-8

Ettman, C. K., Abdalla, S. M., Cohen, G. H., Sampson, L., Vivier, P. M., \& Galea, S. (2020). Prevalence of Depression Symptoms in US Adults Before and During the COVID-19 Pandemic. JAMA Network Open, 3(9), e2019686. https://doi.org/10.1001/jamanetworkopen.2020. 19686

Fancourt, D., Steptoe, A., \& Bu, F. (2020). Trajectories of anxiety and depressive symptoms during enforced isolation due to COVID-19: Longitudinal analyses of 36,520 adults in England. MedRxiv, 2020.06.03.20120923. https://doi.org/10.1101/2020.06.03.20120923

Flora, D. B., \& Curran, P. J. (2004). An empirical evaluation of alternative methods of estimation for confirmatory factor analysis with ordinal data. Psychological Methods, 9(4), 466-491. https://doi.org/10.1037/1082-989X.9.4.466

Grubbs, J. B. (2020, April 12). Big Number: 18\%. Boston Sunday Globe, K2.

Grubbs, J. B., Exline, J. J., Pargament, K. I., Volk, F., \& Lindberg, M. J. (2017). Internet Pornography Use, Perceived Addiction, and Religious/Spiritual Struggles. Archives of Sexual Behavior, 46(6), 1733-1745. https://doi.org/10.1007/s10508-016-0772-9

Grubbs, J. B., \& Gola, M. (2019). Is pornography use related to erectile functioning? Results from cross-sectional and latent growth curve analyses. The Journal of Sexual Medicine, 16(1), 111-125. https://doi.org/10.1016/j.jsxm.2018.11.004

Grubbs, J. B., \& Kraus, S. W. (2021). Pornography Use and Psychological Science: A Call for Consideration. Current Directions in Psychological Science, 096372142097959. https://doi.org/10.1177/0963721420979594

Grubbs, J. B., Kraus, S. W., Perry, S. L., Lewczuk, K., \& Gola, M. (2020). Moral incongruence and compulsive sexual behavior: Results from cross-sectional interactions and parallel growth curve analyses. Journal of Abnormal Psychology, 129(3), 266-278. https://doi.org/10.1037/abn0000501

Grubbs, J. B., Perry, S. L., Wilt, J. A., \& Reid, R. C. (2019). Pornography problems due to moral incongruence: An integrative model with a systematic review and meta-analysis. Archives of Sexual Behavior, 48(2), 397-415. https://doi.org/10.1007/s10508-018-1248-x

Grubbs, J. B., Sessoms, J., Wheeler, D. M., \& Volk, F. (2010). The Cyber-Pornography Use Inventory: The development of a new assessment instrument. Sexual Addiction \& Compulsivity, 17(2), 106-126. https://doi.org/10.1080/10720161003776166

Grubbs, J. B., Tosi, J., \& Warmke, B. (2019). Status seeking and public discourse ethics: A nationally representative sample with longitudinal follow-up. https://doi.org/10.17605/OSF.IO/ZBG3D

Grubbs, J. B., Volk, F., Exline, J. J., \& Pargament, K. I. (2015). Internet pornography use: Perceived addiction, psychological distress, and the validation of a brief measure. Journal of Sex $\mathcal{E}$ 
Marital Therapy, 41(1), 83-106.

https://doi.org/10.1080/0092623X.2013.842192

Grubbs, J. B., Wright, P. J., Braden, A. L., Wilt, J. A., \& Kraus, S. W. (2019). Internet pornography use and sexual motivation: A systematic review and integration. Annals of the International Communication Association, 43(2), 117-155. https://doi.org/10.1080/23808985.2019.1584045

Guidry, R., Floyd, C. G., Volk, F., \& Moen, C. E. (2019). The Exacerbating Impact of Moral Disapproval on the Relationship Between Pornography Use and Depression, Anxiety, and Relationship Satisfaction. Journal of Sex $\mathcal{E}$ Marital Therapy, 0(0), 1-19. https://doi.org/10.1080/0092623X.2019.1654579

Guntuku, S. C., Sherman, G., Stokes, D. C., Agarwal, A. K., Seltzer, E., Merchant, R. M., \& Ungar, L. H. (2020). Tracking Mental Health and Symptom Mentions on Twitter During COVID-19. Journal of General Internal Medicine, 35(9), 2798-2800. https://doi.org/10.1007/s11606-020-05988-8

Håkansson, A., Fernández-Aranda, F., Menchón, J. M., Potenza, M. N., \& Jiménez-Murcia, S. (2020). Gambling during the COVID-19 crisis-A cause for concern? Journal of Addiction Medicine.

Honaker, J., King, G., \& Blackwell, M. (2011). Amelia II: A Program for Missing Data. Journal of Statistical Software, 45(1), 1-47. https://doi.org/10.18637/jss.v045.i07

Jorgensen, T. D., Pornprasertmanit, S., Schoemann, A. M., Rosseel, Y., Miller, P., Quick, C., GarnierVillarreal, M., Selig, J., Boulton, A., Preacher, K., Coffman, D., Rhemtulla, M., Robitzsch, A., Enders, C., Arslan, R., Clinton, B., Panko, P., Merkle, E., Chesnut, S., ... Ben-Shachar, M. S. (2020). semTools: Useful Tools for Structural Equation Modeling (0.5-3) [Computer software]. https://CRAN.R-project.org/package=semTools

Király, O., Potenza, M. N., Stein, D. J., King, D. L., Hodgins, D. C., Saunders, J. B., Griffiths, M. D., Gjoneska, B., Billieux, J., Brand, M., Abbott, M. W., Chamberlain, S. R., Corazza, O., Burkauskas, J., Sales, C. M. D., Montag, C., Lochner, C., Grünblatt, E., Wegmann, E., ... Demetrovics, Z. (2020). Preventing problematic internet use during the COVID-19 pandemic: Consensus guidance. Comprehensive Psychiatry, $100,152180$. https://doi.org/10.1016/j.comppsych.2020.15218 0

Kraus, S. W., \& Rosenberg, H. (2014). The Pornography Craving Questionnaire: Psychometric properties. Archives of Sexual Behavior, 43(3), 451-462. https://doi.org/10.1007/s10508-0130229-3

Kroenke, K., Spitzer, R. L., \& Williams, J. B. W. (2001). The PHQ-9: Validity of a brief depression severity measure. Journal of General Internal Medicine, 16(9), 606-613. https://doi.org/10.1046/j.15251497.2001.016009606.x

Kroenke, K., Spitzer, R. L., Williams, J. B. W., \& Löwe, B. (2009). An Ultra-Brief Screening Scale for Anxiety and Depression: The PHQ-4. Psychosomatics, 50(6), 613-621. https://doi.org/10.1016/S0033-3182(09)70864-3

Leonhardt, N. D., \& Willoughby, B. J. (2019). Pornography, provocative sexual media, and their differing associations with multiple aspects of sexual satisfaction. Journal of Social and Personal Relationships, 36(2), 618-641. https://doi.org/10.1177/0265407517739162

Leonhardt, N. D., Willoughby, B. J., \& Young-Petersen, B. (2018). Damaged Goods: Perception of Pornography Addiction as a Mediator Between Religiosity and Relationship Anxiety Surrounding Pornography Use. Journal of Sex Research, 55(3), 357-368. https://doi.org/10.1080/00224499.2017.1295013

Li, C.-H. (2016). Confirmatory factor analysis with ordinal data: Comparing robust maximum likelihood and diagonally weighted least squares. Behavior Research Methods, 48(3), 936949. https://doi.org/10.3758/s13428-015-0619-7

Luchetti, M., Lee, J. H., Aschwanden, D., Sesker, A., Strickhouser, J. E., Terracciano, A., \& Sutin, A. R. (2020). The trajectory of loneliness in response to COVID-19. American Psychologist, 75(7), 897-908. https://doi.org/10.1037/amp0000690

Lumley, T. (2019). mitools: Tools for Multiple Imputation of Missing Data (2.4) [Computer software]. https://CRAN.R-project.org/package=mitools

Matrajt, L., \& Leung, T. (2020). Evaluating the Effectiveness of Social Distancing Interventions to Delay or Flatten the Epidemic Curve of Coronavirus Disease. Emerging Infectious 
Diseases, 26(8), 1740-1748.

https://doi.org/10.3201/eid2608.201093

Mestre-Bach, G., Blycker, G. R., \& Potenza, M. N. (2020). Pornography use in the setting of the COVID-19 pandemic. Journal of Behavioral Addictions, 1(aop).

https://doi.org/10.1556/2006.2020.00015

Mîndrilă, D. (2010). Maximum Likelihood (ML) and Diagonally Weighted Least Squares (DWLS)

Estimation Procedures: A Comparison of Estimation Bias with Ordinal and Multivariate Non-Normal Data. International Journal for Digital Society, 1(1), 60-66.

https://doi.org/10.20533/ijds.2040.2570.2010.001 0

Paul, B., \& Shim, J. W. (2008). Gender, sexual affect, and motivations for internet pornography use. International Journal of Sexual Health, 20(3), 187199. https://doi.org/10.1080/19317610802240154

Perry, S. L. (2019a). Where Does Masturbation Fit in All This? We Need to Incorporate Measures of Solo-Masturbation in Models Connecting Sexual Media Use to Sexual Quality (or Anything Else). Archives of Sexual Behavior. https://doi.org/10.1007/s10508-018-1379-0

Perry, S. L. (2019b). Addicted to lust: Pornography in the lives of conservative protestants. Oxford University Press.

Pierce, M., Hope, H., Ford, T., Hatch, S., Hotopf, M., John, A., Kontopantelis, E., Webb, R., Wessely, S., McManus, S., \& Abel, K. M. (2020). Mental health before and during the COVID-19 pandemic: A longitudinal probability sample survey of the UK population. The Lancet Psychiatry, 7(10), 883-892.

https://doi.org/10.1016/S2215-0366(20)30308-4

Pornhub Insights. (2020, March 23). Coronavirus Insights - Pornhub Insights.

https://www.pornhub.com/insights/coronavirus

R Core Team. (2018). R: A Language and Environment for Statistical Computing. R Foundation for Statistical Computing. https://www.Rproject.org/

Reid, R. C., Li, D. S., Gilliland, R., Stein, J. A., \& Fong, T. (2011). Reliability, validity, and psychometric development of the pornography consumption inventory in a sample of hypersexual men.
Journal of Sex \& Marital Therapy, 37(5), 359-385. https://doi.org/10.1080/0092623X.2011.607047

Revelle, W. (2014). psych: Procedures for psychological, psychometric, and personality research. Northwestern University, Evanston, Illinois, 165.

Rosseel, Y. (2012). lavaan: An R package for structural equation modeling and more Version 0.5-12 (BETA). Journal of Statistical Software, 42, 1-36.

Rothman, E. F., Kaczmarsky, C., Burke, N., Jansen, E., \& Baughman, A. (2015). "Without porn ... i wouldn't know half the things i know now": A qualitative study of pornography use among a sample of urban, low-income, Black and Hispanic youth. The Journal of Sex Research, 52(7), 736-746. https://doi.org/10.1080/00224499.2014.960908

Rubin, D. B. (1987). Multiple imputation for survey nonresponse.

Schenk, C. (2009). Pornography as a leisure behavior: An investigation of pornography use and leisure boredom. All Theses and Dissertations. https://scholarsarchive.byu.edu/etd/1976

Sinclair, D. L., Vanderplasschen, W., Savahl, S., Florence, M., Best, D., \& Sussman, S. (2020). Substitute addictions in the context of the COVID-19 pandemic. Journal of Behavioral Addictions.

Spitzer, R. L., Kroenke, K., Williams, J. B., \& Löwe, B. (2006). A brief measure for assessing generalized anxiety disorder: The GAD-7. Archives of Internal Medicine, 166(10), 1092-1097.

The 2019 Year in Review - Pornhub Insights. (2019, December 11). Pornhub. https://www.pornhub.com/insights/2019-yearin-review

Turak, N. (2020, March 20). Pornhub is offering free premium memberships to countries on coronavirus lockdown, sees traffic leap. CNBC. https://www.cnbc.com/2020/03/20/coronaviruslockdown-pornhub-is-offering-free-premiummemberships.html

Wang, W. C., \& Cunningham, E. G. (2005). Comparison of alternative estimation methods in confirmatory factor analyses of the General Health Questionnaire. Psychological Reports, 97(1), 3-10. https://doi.org/10.2466/pr0.97.1.3-10

Willoughby, B. J., \& Leonhardt, N. D. (2020). Behind Closed Doors: Individual and Joint Pornography Use Among Romantic Couples. 
Porndemic

The Journal of Sex Research, 57(1), 77-91. https://doi.org/10.1080/00224499.2018.1541440

Wilson, A. (2020, April). Help Flatten the Curve with Free Pornhub Premium Blog-Free Porn Videos E Sex Movies - Porno, XXX, Porn Tube and Pussy Porn. https://www.pornhub.com/blog/9891

Yoder, V. C., Virden III, T. B., \& Amin, K. (2005). Internet pornography and loneliness: An association? Sexual Addiction \& Compulsivity, 12(1), 19-44.

Zacher, H., \& Rudolph, C. W. (2021). Individual differences and changes in subjective wellbeing during the early stages of the COVID-19 pandemic. American Psychologist, 76(1), 50-62. https://doi.org/10.1037/amp0000702

Zattoni, F., Gül, M., Soligo, M., Morlacco, A., Motterle, G., Collavino, J., Barneschi, A. C., Moschini, M., \& Moro, F. D. (2020). The impact of COVID-19 pandemic on pornography habits: A global analysis of Google Trends. International Journal of Impotence Research, 1-8. https://doi.org/10.1038/s41443-020-00380-w 
Table 1

Descriptive Statistics and Pearson Correlations with Holm-adjusted test statistics for key variables.

\begin{tabular}{|c|c|c|c|c|c|c|c|c|c|c|c|c|c|c|c|c|c|}
\hline & $\begin{array}{l}\text { Mean } \\
(\mathrm{SD})\end{array}$ & Range & & 1 & 2 & 3 & 4 & 5 & 6 & 7 & 8 & 9 & 10 & 11 & 12 & 13 & 14 \\
\hline 1. T1 PHQ-4a & $\begin{array}{c}1.84 \\
(0.85)\end{array}$ & $1-4$ & & & & & & & & & & & & & & & \\
\hline 2. T2 PHQ-4 & $\begin{array}{c}1.76 \\
(0.82)\end{array}$ & $1-4$ & $\begin{array}{l}\alpha=.90 \\
\omega=.90\end{array}$ & .67 & & & & & & & & & & & & & \\
\hline 3. T3 PHQ-4c & $\begin{array}{c}1.75 \\
(0.82)\end{array}$ & $1-4$ & $\begin{array}{l}\alpha=.90 \\
\omega=.91\end{array}$ & .66 & .69 & & & & & & & & & & & & \\
\hline 4. T4 PHQ-4d & $\begin{array}{c}1.73 \\
(0.81)\end{array}$ & $1-4$ & $\begin{array}{l}\alpha=.91 \\
\omega=.93\end{array}$ & .67 & .69 & .73 & & & & & & & & & & & \\
\hline 5. T5 PHQ-4e & $\begin{array}{l}1.76 \\
(0.84)\end{array}$ & $1-4$ & $\begin{array}{l}\alpha=.91 \\
\omega=.91\end{array}$ & .69 & .68 & .73 & .77 & & & & & & & & & & \\
\hline $\begin{array}{l}\text { 6. T1 Self-Reported } \\
\text { Problems }^{\mathrm{f}}\end{array}$ & $\begin{array}{c}2.24 \\
(1.56)\end{array}$ & $1-7$ & $\begin{array}{l}\alpha=.91 \\
\omega=.91\end{array}$ & .27 & .18 & .12 & .08 & .14 & & & & & & & & & \\
\hline $\begin{array}{l}\text { 7. T2 Self-Reported } \\
\text { Problems }\end{array}$ & $\begin{array}{l}2.15 \\
(1.43)\end{array}$ & $1-7$ & $\begin{array}{l}\alpha=.90 \\
\omega=.90\end{array}$ & .21 & .25 & .12 & .10 & .15 & .73 & & & & & & & & \\
\hline $\begin{array}{l}\text { 8. T3 Self-Reported } \\
\text { Problems }{ }^{\mathrm{h}}\end{array}$ & $\begin{array}{c}2.13 \\
(1.35)\end{array}$ & $1-7$ & $\begin{array}{l}\alpha=.88 \\
\omega=.88\end{array}$ & .16 & .18 & .19 & .09 & .10 & .71 & .75 & & & & & & & \\
\hline $\begin{array}{l}\text { 9. T4 Self-Reported } \\
\text { Problems } \mathrm{s}^{\mathrm{i}}\end{array}$ & $\begin{array}{c}2.06 \\
(1.33)\end{array}$ & $1-7$ & $\begin{array}{l}\alpha=.89 \\
\omega=.89\end{array}$ & .13 & .16 & .15 & .17 & .12 & .72 & .73 & .73 & & & & & & \\
\hline $\begin{array}{l}\text { 10. T5 Self-Reported } \\
\text { Problemsi }\end{array}$ & $\begin{array}{l}2.08 \\
(1.38)\end{array}$ & $1-7$ & $\begin{array}{l}\alpha=.88 \\
\omega=.89\end{array}$ & .19 & .20 & .13 & .13 & .21 & .72 & .73 & .78 & .78 & & & & & \\
\hline 11. T1 Frequencya & $\begin{array}{l}0.99 \\
(1.6)\end{array}$ & $0-5$ & & .13 & .08 & .10 & .04 & .08 & .26 & .16 & .12 & .21 & .03 & & & & \\
\hline 12. T2 Frequency & $\begin{array}{c}0.83 \\
(1.52)\end{array}$ & $0-5$ & & .11 & .10 & .08 & .08 & .10 & .33 & .33 & .25 & .27 & .24 & .71 & & & \\
\hline 13. T3 Frequencyc & $\begin{array}{c}0.92 \\
(1.46)\end{array}$ & $0-5$ & & .15 & .11 & .11 & .10 & .12 & .41 & .39 & .34 & .38 & .37 & .72 & .76 & & \\
\hline 14. T4 Frequency & $\begin{array}{c}0.73 \\
(1.49)\end{array}$ & $0-5$ & & .13 & .10 & .11 & .11 & .13 & .33 & .29 & .19 & .27 & .26 & .67 & .74 & .75 & \\
\hline 15. T5 Frequency & $\begin{array}{c}0.69 \\
(1.47)\end{array}$ & $0-5$ & & .13 & .06 & .10 & .10 & .12 & .30 & .23 & .21 & .31 & .28 & .67 & .74 & .78 & .79 \\
\hline
\end{tabular}

T1=August 2019; T2=Feb 2020; T3=May 2020; T4=August 2020, T5 = October 2020; PHQ-4 = Patient Health Questionnaire-4. $\alpha=$ Cronbach's Alpha; $\omega=$ McDonald's Omega Total

All correlations for which $\mathrm{r}>|.10|$ are significant at $\mathrm{p}<.05$ with Holm-adjusted test statistics. All correlations for which $\mathrm{r}>|.13|$ are significant at $\mathrm{p}<.001$ with Holmadjusted test statistics.

${ }_{\mathrm{a}} n=2,518, \mathrm{~b}_{n}=1,677, \mathrm{c} n=1,533, \mathrm{~d} n=1,470,{ }_{\mathrm{e}} \mathrm{n}=1,269 \mathrm{f}_{n}=1,455, \mathrm{~g}_{n}=846,{ }^{\mathrm{h}} n=577,{ }^{\mathrm{i}} n=619, \mathrm{j}=518$

For frequency of pornography use: $0=$ not within the past month, $1=$ within the past month, $2=$ two or three times a month, $3=$ once a week, $4=\mathrm{a}$ few times a week, and $5=$ once a day or more. 


\section{Table 2}

Frequency of pornography use by gender at each time point.

\begin{tabular}{|c|c|c|c|c|c|c|c|c|c|c|c|c|c|c|c|}
\hline & \multicolumn{3}{|c|}{$\begin{array}{c}\text { Wave } 1 \\
\text { August, } 2019 \\
N=2,518 \\
\text { Men, } n=1,113 \\
\text { Women, } n=1,386\end{array}$} & \multicolumn{3}{|c|}{$\begin{array}{c}\text { Wave } 2 \\
\text { February, } 2020 \\
n=1,677 \\
\text { Men, } n=749 \\
\text { Women, } n=929\end{array}$} & \multicolumn{3}{|c|}{$\begin{array}{c}\text { Wave } 3 \\
\text { May, } 2020 \\
n=1,533 \\
\text { Men, } n=687 \\
\text { Women, } n=846\end{array}$} & \multicolumn{3}{|c|}{$\begin{array}{c}\text { Wave } 4 \\
\text { August, } 2020 \\
n=1,470 \\
\text { Men, } n=678 \\
\text { Women, } n=792\end{array}$} & \multicolumn{3}{|c|}{$\begin{array}{c}\text { Wave } 5 \\
\text { October, } 2020 \\
n=1,269 \\
\text { Men, } n=560 \\
\text { Women, } n=709\end{array}$} \\
\hline & $\begin{array}{c}\text { Total } \\
\% \\
(\mathrm{n}) \\
\end{array}$ & $\begin{array}{c}\text { Men } \\
\% \\
(\mathrm{n}) \\
\end{array}$ & $\begin{array}{c}\text { Women } \\
\% \\
(\mathrm{n}) \\
\end{array}$ & $\begin{array}{c}\text { Total } \\
\% \\
(\mathrm{n}) \\
\end{array}$ & $\begin{array}{c}\text { Men } \\
\% \\
(\mathrm{n}) \\
\end{array}$ & $\begin{array}{c}\text { Women } \\
\% \\
(\mathrm{n}) \\
\end{array}$ & $\begin{array}{c}\text { Total } \\
\% \\
(\mathrm{n}) \\
\end{array}$ & $\begin{array}{c}\text { Men } \\
\% \\
(\mathrm{n}) \\
\end{array}$ & $\begin{array}{c}\text { Women } \\
\% \\
(\mathrm{n}) \\
\end{array}$ & $\begin{array}{c}\text { Total } \\
\% \\
(\mathrm{n}) \\
\end{array}$ & $\begin{array}{c}\text { Men } \\
\% \\
(\mathrm{n}) \\
\end{array}$ & $\begin{array}{c}\text { Women } \\
\% \\
(\mathrm{n}) \\
\end{array}$ & $\begin{array}{c}\text { Total } \\
\% \\
(\mathrm{n}) \\
\end{array}$ & $\begin{array}{c}\text { Men } \\
\% \\
(\mathrm{n}) \\
\end{array}$ & $\begin{array}{c}\text { Women } \\
\% \\
(\mathrm{n}) \\
\end{array}$ \\
\hline Never & $\begin{array}{c}68 \% \\
(1715)\end{array}$ & $\begin{array}{c}47.3 \% \\
(535)\end{array}$ & $\begin{array}{l}85.1 \% \\
(1180)\end{array}$ & $\begin{array}{c}73 \% \\
(1228)\end{array}$ & $\begin{array}{l}55.2 \% \\
(413)\end{array}$ & $\begin{array}{c}87.7 \% \\
(815)\end{array}$ & $\begin{array}{l}64 \% \\
(976)\end{array}$ & $\begin{array}{l}41.8 \% \\
(287)\end{array}$ & $\begin{array}{c}81.4 \% \\
(689)\end{array}$ & $\begin{array}{c}78 \% \\
(1148)\end{array}$ & $\begin{array}{c}62.1 \% \\
(421)\end{array}$ & $\begin{array}{l}91.8 \% \\
(727)\end{array}$ & $\begin{array}{l}79.4 \% \\
(1008)\end{array}$ & $\begin{array}{c}62.7 \% \\
(351)\end{array}$ & $\begin{array}{l}92.7 \% \\
(657)\end{array}$ \\
\hline $\begin{array}{l}\text { Once or } \\
\text { twice }\end{array}$ & $\begin{array}{l}4 \% \\
(98)\end{array}$ & $\begin{array}{c}5.1 \% \\
(58)\end{array}$ & $\begin{array}{l}2.8 \% \\
(40)\end{array}$ & $\begin{array}{l}4 \% \\
(70)\end{array}$ & $\begin{array}{l}5.2 \% \\
(39)\end{array}$ & $\begin{array}{c}3.3 \% \\
(31)\end{array}$ & $\begin{array}{l}10 \% \\
(159)\end{array}$ & $\begin{array}{c}13.2 \% \\
(91)\end{array}$ & $\begin{array}{c}8.0 \% \\
(68)\end{array}$ & $\begin{array}{l}2 \% \\
(28)\end{array}$ & $\begin{array}{c}2.2 \% \\
(15)\end{array}$ & $\begin{array}{c}1.6 \% \\
(13)\end{array}$ & $\begin{array}{c}2.0 \% \\
(26)\end{array}$ & $\begin{array}{c}3.0 \% \\
(17)\end{array}$ & $\begin{array}{c}1.3 \% \\
(9)\end{array}$ \\
\hline $\begin{array}{c}\text { Two or } \\
\text { three } \\
\text { times }\end{array}$ & $\begin{array}{c}8 \% \\
(192)\end{array}$ & $\begin{array}{c}10.8 \% \\
(122)\end{array}$ & $\begin{array}{l}5.1 \% \\
(70)\end{array}$ & $\begin{array}{l}5 \% \\
(89)\end{array}$ & $\begin{array}{c}8.7 \% \\
(65)\end{array}$ & $\begin{array}{c}2.6 \% \\
(24)\end{array}$ & $\begin{array}{l}11 \% \\
(169)\end{array}$ & $\begin{array}{c}16.6 \% \\
(114)\end{array}$ & $\begin{array}{c}6.5 \% \\
(55)\end{array}$ & $\begin{array}{l}4 \% \\
(60)\end{array}$ & $\begin{array}{l}5.6 \% \\
(38)\end{array}$ & $\begin{array}{c}2.8 \% \\
(22)\end{array}$ & $\begin{array}{c}3.6 \% \\
(46)\end{array}$ & $\begin{array}{c}4.8 \% \\
(27)\end{array}$ & $\begin{array}{c}2.7 \% \\
(19)\end{array}$ \\
\hline $\begin{array}{l}\text { Once a } \\
\text { week }\end{array}$ & $\begin{array}{c}6 \% \\
(143)\end{array}$ & $\begin{array}{l}9.7 \% \\
(110)\end{array}$ & $\begin{array}{c}2.3 \% \\
(33)\end{array}$ & $\begin{array}{l}5 \% \\
(77)\end{array}$ & $\begin{array}{c}6.4 \% \\
(48)\end{array}$ & $\begin{array}{c}3.1 \% \\
(29)\end{array}$ & $\begin{array}{l}3 \% \\
(52)\end{array}$ & $\begin{array}{c}5.8 \% \\
(40)\end{array}$ & $\begin{array}{c}1.4 \% \\
(12)\end{array}$ & $\begin{array}{l}4 \% \\
(56)\end{array}$ & $\begin{array}{l}6.9 \% \\
(47)\end{array}$ & $\begin{array}{l}1.1 \% \\
(9)\end{array}$ & $\begin{array}{c}2.9 \% \\
(37)\end{array}$ & $\begin{array}{l}5.4 \% \\
(30)\end{array}$ & $\begin{array}{c}1.0 \% \\
(7)\end{array}$ \\
\hline $\begin{array}{l}\text { A few } \\
\text { times a } \\
\text { week }\end{array}$ & $\begin{array}{l}11 \% \\
(277)\end{array}$ & $\begin{array}{c}20.5 \% \\
(232)\end{array}$ & $\begin{array}{c}3.2 \% \\
(45)\end{array}$ & $\begin{array}{l}9 \% \\
(156)\end{array}$ & $\begin{array}{c}17.6 \% \\
(132)\end{array}$ & $\begin{array}{c}2.6 \% \\
(24)\end{array}$ & $\begin{array}{c}9 \% \\
(132)\end{array}$ & $\begin{array}{c}16.3 \% \\
(112)\end{array}$ & $\begin{array}{c}2.4 \% \\
(20)\end{array}$ & $\begin{array}{c}9 \% \\
(131)\end{array}$ & $\begin{array}{c}16.8 \% \\
(114)\end{array}$ & $\begin{array}{c}2.1 \% \\
(17)\end{array}$ & $\begin{array}{l}8.7 \% \\
(111)\end{array}$ & $\begin{array}{c}17.3 \% \\
(97)\end{array}$ & $\begin{array}{c}2.0 \% \\
(14)\end{array}$ \\
\hline $\begin{array}{l}\text { Once a } \\
\text { day or } \\
\text { more }\end{array}$ & $\begin{array}{l}4 \% \\
(93)\end{array}$ & $\begin{array}{c}6.6 \% \\
(75)\end{array}$ & $\begin{array}{c}1.3 \% \\
(18)\end{array}$ & $\begin{array}{l}3 \% \\
(57)\end{array}$ & $\begin{array}{c}6.8 \% \\
(51)\end{array}$ & $\begin{array}{c}0.6 \% \\
(6)\end{array}$ & $\begin{array}{l}3 \% \\
(45)\end{array}$ & $\begin{array}{l}6.3 \% \\
(43)\end{array}$ & $\begin{array}{c}0.2 \% \\
(2)\end{array}$ & $\begin{array}{l}3 \% \\
(47)\end{array}$ & $\begin{array}{l}6.3 \% \\
(43)\end{array}$ & $\begin{array}{l}0.5 \% \\
(4)\end{array}$ & $\begin{array}{c}79.4 \% \\
(41)\end{array}$ & $\begin{array}{c}6.8 \% \\
(38)\end{array}$ & $\begin{array}{l}0.4 \% \\
(3)\end{array}$ \\
\hline
\end{tabular}


Table 3

Univariate Latent Growth Curve Models

\begin{tabular}{|c|c|c|c|c|c|c|}
\hline & Mean & $\mathrm{SE}$ & $\mathrm{p}$-value & Variance & SE & $\mathrm{p}$-value \\
\hline $\begin{array}{l}\text { Psychological Distress Intercept for } \\
\text { Men }\end{array}$ & 1.73 & .03 & $<.001$ & 0.43 & 0.04 & $<.001$ \\
\hline Psychological Distress Slope for Men & -0.00 & 0.00 & .542 & 0.00 & 0.00 & .924 \\
\hline $\begin{array}{l}\text { Standardized Intercept-Slope } \\
\text { covariance for Men }\end{array}$ & \multicolumn{6}{|c|}{$r=0.65, p=.340$} \\
\hline $\begin{array}{l}\text { Psychological Distress Intercept for } \\
\text { Women }\end{array}$ & 1.90 & 0.03 & $<.001$ & 0.46 & 0.03 & $<.001$ \\
\hline $\begin{array}{l}\text { Psychological Distress Slope for } \\
\text { Women }\end{array}$ & 0.00 & 0.01 & .798 & 0.00 & 0.00 & .396 \\
\hline $\begin{array}{l}\text { Standardized Intercept-Slope } \\
\text { Covariance for Women }\end{array}$ & \multicolumn{6}{|c|}{$r=0.34, p=.128$} \\
\hline
\end{tabular}

Overall Model Fit for Psychological Distress $\chi^{2}(20)=46.36, p=.001$

$\mathrm{CFI}=.991, \mathrm{TLI}=.991, \mathrm{RMSEA}=.016, \mathrm{SRMR}=.022$

\begin{tabular}{|c|c|c|c|c|c|c|}
\hline Pornography Use Intercept for Men & 2.05 & 0.07 & $<.001$ & 2.51 & 0.13 & $<.001$ \\
\hline Pornography Use Slope for Men & -0.16 & 0.01 & $<.001$ & 0.01 & 0.01 & .425 \\
\hline $\begin{array}{l}\text { Standardized Intercept-Slope } \\
\text { Covariance for Men }\end{array}$ & \multicolumn{6}{|c|}{$r=0.42, p=.053$} \\
\hline $\begin{array}{l}\text { Pornography Use Intercept for } \\
\text { Women }\end{array}$ & 0.59 & 0.04 & $<.001$ & 0.94 & 0.10 & $<.001$ \\
\hline Pornography Use Slope for Women & -0.07 & 0.01 & $<.001$ & 0.01 & 0.01 & .072 \\
\hline $\begin{array}{l}\text { Standardized Intercept-Slope } \\
\text { Covariance for Women }\end{array}$ & \multicolumn{6}{|c|}{$r=-.58, p=.003$} \\
\hline
\end{tabular}

Overall Model Fit for Pornography Use Frequency

$$
\chi 2(20)=194.36, p=<.001
$$

$\mathrm{CFI}=.988, \mathrm{TLI}=1.00, \mathrm{RMSEA}=.043, \mathrm{SRMR}=.038$

\begin{tabular}{|c|c|c|c|c|c|c|}
\hline PPU Intercept for Men & 2.34 & 0.08 & $<.001$ & 1.74 & 0.19 & $<.001$ \\
\hline PPU Slope for Men & -0.05 & 0.01 & $<.001$ & 0.01 & 0.01 & .149 \\
\hline $\begin{array}{l}\text { Standardized Intercept-Slope } \\
\text { Covariance for Men }\end{array}$ & \multicolumn{6}{|c|}{$r=-.40(p=.069)$} \\
\hline PPU Intercept for Women & 1.59 & 0.07 & $<.001$ & 1.51 & 0.19 & $<.001$ \\
\hline PPU Slope for Women & -0.01 & 0.01 & .350 & 0.01 & 0.01 & .175 \\
\hline $\begin{array}{l}\text { Standardized Intercept-Slope } \\
\text { Covariance for Women }\end{array}$ & \multicolumn{6}{|c|}{$r=-.399, p=.087$} \\
\hline \multicolumn{7}{|c|}{$\begin{array}{l}\text { Overall Model Fit for Problematic Pornography Use } \\
\qquad \chi 2(20)=4.54, p=1.00 \\
\text { CFI }=1.00, \text { TLI }=1.00, \text { RMSEA }=.000 \text { SRMR }=.022\end{array}$} \\
\hline
\end{tabular}


Table 4

Intercept, Slope, and Model Fit Statistics for Parallel Latent Growth Curve Model

Dual Process Parallel Growth Curve:

Pornography Use and Self-Reported Problems with Intercept Only Psychological Distress

\begin{tabular}{|c|c|c|c|c|c|c|}
\hline & Mean & SE & $\mathrm{p}$-value & Variance & SE & $\mathrm{p}$-value \\
\hline & \multicolumn{6}{|c|}{ For Men } \\
\hline Psychological Distress Intercept & 1.72 & 0.03 & $<.001$ & 0.47 & 0.03 & $<.001$ \\
\hline Pornography Use Intercept & 2.05 & 0.08 & $<.001$ & 3.42 & 0.11 & $<.001$ \\
\hline Pornography Use Slope & -0.16 & 0.01 & $<.001$ & 0.07 & 0.01 & $<.001$ \\
\hline \multirow{3}{*}{$\begin{array}{l}\text { PPU Intercept } \\
\text { PPU Slope }\end{array}$} & 2.34 & 0.06 & $<.001$ & 1.86 & 0.14 & $<.001$ \\
\hline & -0.05 & 0.01 & $<.001$ & 0.02 & 0.00 & $<.001$ \\
\hline & \multicolumn{6}{|c|}{ For Women } \\
\hline Psychological Distress Intercept & 1.90 & 0.03 & $<.001$ & 0.52 & 0.03 & $<.001$ \\
\hline Pornography Use Intercept & 0.59 & 0.05 & $<.001$ & 1.22 & 0.12 & $<.001$ \\
\hline Pornography Use Slope & -0.07 & 0.01 & $<.001$ & 0.03 & 0.00 & $<.001$ \\
\hline PPU Intercept & 1.59 & 0.05 & $<.001$ & 1.63 & 0.14 & $<.001$ \\
\hline \multirow[t]{2}{*}{ PPU Slope } & -0.01 & 0.01 & .212 & 0.02 & 0.00 & $<.001$ \\
\hline & $\begin{array}{r}\text { Over: } \\
\chi 2(2 \\
00, \mathrm{TLI}=\end{array}$ & $\begin{array}{l}\text { Todel Fit } \\
=213.10, \\
\text {, RMSEA }\end{array}$ & $\begin{array}{l}\text { tistics } \\
.543 \\
.000, \text { SRM }\end{array}$ & $=.038$ & & \\
\hline
\end{tabular}

$\mathrm{PPU}=$ Self-Reported Problems with Pornography Use; $\mathrm{SE}=$ standard error 


\section{Table 5}

Standardized covariances (i.e., correlations) between latent intercepts and slopes for parallel process growth curve model of problematic pornography use and use frequency with intercept only psychological distress.

\begin{tabular}{|c|c|c|c|c|c|c|}
\hline & & & Standar & variance fo & & \\
\hline & & Psychological Distress & & & & \\
\hline & & Intercept & Use Intercept & Use Slope & PPU Intercept & PPU Slope \\
\hline$e^{+1}$ & $\begin{array}{r}\text { Psychological } \\
\text { Distress }\end{array}$ & - & $.198^{* *}$ & .023 & $.369 * *$ & -.090 \\
\hline & Intercept & & & & & \\
\hline 常 & Use Intercept & $.261^{* *}$ & - & $-.600^{* *}$ & $.330 * *$ & $-.229 * *$ \\
\hline & Use Slope & $-.108 *$ & $-.685^{* *}$ & - & -.059 & $.330 * *$ \\
\hline ఫ్ర్త్ర & PPU Intercept & $.330^{* *}$ & $.358^{* *}$ & $-.192 * *$ & - & $-.469 * *$ \\
\hline 吾 & PPU Slope & -.100 & $-.235^{* *}$ & $.292 * *$ & $-.473 * *$ & - \\
\hline
\end{tabular}

Standardized covariance for women below the diagonal, standardized covariance for men above the diagonal

PPU $=$ Self-Reported Problems with Pornography Use

$* p<.05, * * p<.005$ 